\title{
Lidil
}

Revue de linguistique et de didactique des langues

$55 \mid 2017$

Littéracie et entrée dans l'écrit

\section{Marielle Rispail et Leila Messaoudi (dir.), Des langues minoritaires en contexte plurilingue francophone, revue Cahiers de linguistique} vol. 42, nº 1, 2016, EME Éditions, 283 p.

Valeria Villa-Perez

\section{OpenEdition}

\section{Journals}

Édition électronique

URL : http://journals.openedition.org/lidil/4228

DOI : $10.4000 /$ lidil. 4228

ISSN : $1960-6052$

Éditeur

UGA Éditions/Université Grenoble Alpes

Édition imprimée

ISBN : 978-2-37747-002-0

ISSN : $1146-6480$

\section{Référence électronique}

Valeria Villa-Perez, « Marielle Rispail et Leila Messaoudi (dir.), Des langues minoritaires en contexte plurilingue francophone, revue Cahiers de linguistique », Lidil [En ligne], 55 | 2017, mis en ligne le 02 mai 2017, consulté le 25 septembre 2020. URL : http://journals.openedition.org/lidil/4228 ; DOI : https:// doi.org/10.4000/lidil.4228

Ce document a été généré automatiquement le 25 septembre 2020

(C) Lidil 


\title{
Marielle Rispail et Leila Messaoudi (dir.), Des langues minoritaires en contexte plurilingue francophone, revue Cahiers de linguistique
}

vol. 42, n 1, 2016, EME Éditions, 283 p.

\author{
Valeria Villa-Perez
}

\section{RÉFÉRENCE}

Marielle Rispail et Leila Messaoudi (dir.), Des langues minoritaires en contexte plurilingue francophone, Revue Cahiers de linguistique, vol. 42, nº 1, 2016, EME Éditions, 283 p.

1 Cet ouvrage - hommage à Ahmed Boukous, sociolinguiste, dont le nom est lié aux recherches sur la langue amazighe, sur sa promotion, et sur son enseignement au Maroc - porte un regard pluriel sur les langues minoritaires en contexte plurilingue francophone. Les textes réunis montrent comment l'exemple de l'amazighe au Maroc et en Algérie peut entrer en résonance avec d'autres contextes sociolinguistiques, en soulignant les similitudes, des situations de dépréciation à la quête de reconnaissance, que partagent les langues minorées.

2 Cet aspect émerge par exemple de la riche contribution de Claude Cortier, Alain Di Meglio et Pascal Ottavi, où les politiques de colonisation linguistique du français men ées au Maghreb, sont mises en relation avec le cas des langues régionales en France et notamment du corse. Il est question ici de «statut» des langues, de domination et d'hégémonie linguistique. Mais on est frappé aussi par l'analyse didactique à propos de la «longévité des représentations» (p.26) dans les pratiques enseignantes qui n'encouragent pas l'alternance codique en classe, que ce soit en Algérie ou au Maroc.

3 Si l'attribution d'un statut institutionnel contribue à lutter contre des représentations négatives vis-à-vis des langues minoritaires ou minorées, les rapports des locuteurs 
avec leurs langues n'en demeurent pas moins complexes. Pour l'amazighe, par exemple, l'introduction de cette langue à l'école et à l'université a permis un changement de statut: de «langue vernaculaire dévalorisée à celui prestigieux de langue enseignée » (cf. Ahmed Boukous cité par Zahir Meksem, p. 197). Néanmoins les représentations partagées restent historiquement ancrées dans la langue, ou dans les énoncés proverbiaux, comme le montre une expression courante en arabe darija «zzit ma hi(ya) idam w ch-chelHa ma hi(ya) klam (litt. l'huile n'est pas sauce), le chleuh (langue amazighe) n'est pas klam (parole, langage...) » (p. 42-43). Cela peut aussi expliquer, d'après Abdelkader Bezzazi, les rapports controversés des sujets avec leurs langues, mais aussi les attitudes linguistiques qui en découlent.

4 On connait bien en effet le lien entre représentations et attitudes et/ou comportements langagiers causés par l'uniformisation linguistique. C'est le cas du provençal, décrit par Philippe Blanchet, dont la pratique a sensiblement décru au fil des années au profit du français. La transmission linguistique ayant diminué pendant les dernières décennies, le chercheur propose de revitaliser cette langue en examinant l'hypothèse stimulante de l'approche « polynomique » qui prévoit entre autres la prise en compte de toutes les variétés locales du provençal (p. 94, 100).

On lit de plus avec intérêt dans cet ouvrage les réflexions issues d'une recherche longitudinale menée par Marielle Rispail avec une jeune amazighophone, Rékia. On y apprécie particulièrement les interrogations de la chercheuse sur « la méthodologie de recherche qui a donné forme [à l'entretien]» (p. 250) ainsi que «les modalités d'é mergence [des propos]»(p.251). Les détails méthodologiques illustrés dans la deuxième partie de l'article sont intéressants pour réfléchir à la co-construction de l'entretien avec son informateur.

6 À ce stade, on peut mettre en lumière le fil rouge qui relie les contributions de ce numéro et fait la pertinence de l'ouvrage ; il s'agit de la problématisation du " poids " des langues, pour le dire avec les mots de Louis-Jean Calvet, résultat de l'histoire linguistique et des rapports de force entretenus entre les langues «qui font leur importance respective » (p. 280).

7 Ce poids se manifeste dans les politiques linguistiques et éducatives de différents pays de l'Afrique francophone qui ont connu des dynamiques de substitution des langues locales par la langue dominante, le français. Henri Boyer attire l'attention sur ces processus en revenant sur une pratique attestée dans plusieurs pays (dont la France): l'usage du « symbole », « signale », « signe », objet donné à celui ou à celle qui utilisait à l'école sa langue primaire pour le réprimander de cette pratique langagière (p. 253). L'extrême dureté de ce phénomène, ayant pour but d'éradiquer les "patois", en France, et les langues autochtones dans les anciennes colonies, visait donc la diffusion de « l'unilinguisme » et la destruction de la diversité linguistique.

8 Les principes «d'écologie linguistique » de Louis-Jean Calvet viennent à point pour expliquer d'une part, l'évolution et la sélection (naturelle ?) des langues, et d'autre part, la sauvegarde de la "biodiversité linguistique» (p.271). Parmi les processus d'évolution linguistique, il est intéressant de noter un évènement " perturbant » mais positif, le phénomène d'acclimatation linguistique qui a provoqué la "circulation de mots et d'images, de formes et de formules» dans différents pays en raison de la mobilité des populations (p. 274). Phénomène de circulation des langues encore actuel et distinct selon les contextes de migration, et qu'on retrouve dans le marquage urbain 
plurilingue de certaines villes marocaines où plusieurs idiomes sont en contact avec l' amazighe (cf. Bouchra El Barkani, p. 145).

9 Pour conclure, cet ouvrage a le mérite de mettre la focale sur des contextes pluriels où l'hégémonie d'une seule langue a produit des situations de minoration et de pertes considérables d'hétérogénéité linguistique et, au travers de l'exemple de la revitalisation de l'amazighe, invite « celles et ceux qui croient que la sociolinguistique peut être une action sociale autant qu'une discipline scientifique » (cf. Rispail, p. 252) à réfléchir à des interventions possibles.

\section{AUTEURS}

\section{VALERIA VILLA-PEREZ}

Université Jean Monnet - St-Étienne, laboratoire CELEC 